\title{
Parâmetros físicos e sensoriais de qualidade da carne de cabritos mestiços de diferentes grupos genéticos
}

\author{
Physical and sensory quality parameters of the meat \\ of crossbred goat kids of different genetic groups
}

\begin{abstract}
Antonia Lucivânia de Sousa MONTE ${ }^{1 *}$, Arturo Bernardo SELAIVE-VILLARROEL ${ }^{2}$, Deborah dos Santos GARRUTI ${ }^{3}$, Jorge Fernando Fuentes ZAPATA ${ }^{4}$, Ângela Silva BORGES ${ }^{5}$
\end{abstract}

\begin{abstract}
Resumo
Este trabalho avaliou a qualidade da carne de cabritos mestiços resultantes do cruzamento de animais Sem Raça Definida (SRD) com dois diferentes grupos genéticos, Anglo Nubiana (A) e Boer (B). Foram utilizados 07 animais SRD (controle), sete 1/2 A x 1/2 SRD, sete 3/4 A x 1/4 SRD, sete $1 / 2 \mathrm{~B} \times 1 / 2 \mathrm{SRD}$ e sete $3 / 4 \mathrm{~B} \times 1 / 4 \mathrm{SRD}$. Os parâmetros estudados foram $\mathrm{pH}\left(\mathrm{pH}_{0}-30\right.$ minutos e $\mathrm{pHf}-24$ horas), cor (L*, a*, b*), capacidade de retenção de água (CRA), perda de peso na cocção (PPC), força de cisalhamento (FC), suculência, dureza e sabor. O pH 30 minutos foi de 6,92 nos SRD, diferindo significativamente apenas do grupo Boer (6,80 nos 1/2 B e 6,84 nos 3/4 B). O pH 24 horas foi de 5,64 para SRD, 5,42 para $1 / 2$ A, 5,77 para $3 / 4$ A, 5,59 para $1 / 2$ B, e 5,55 para 3/4 B. As amostras $1 / 2 \mathrm{~B}$ e $3 / 4$ B apresentaram valores diferentes para $\mathrm{L}^{*}$, mas não diferiram quanto à $\mathrm{a}^{*} \mathrm{e} \mathrm{b}^{*}$. A carne dos animais mestiços reteve maior quantidade de água, apresentando menor perda de peso na cocção e menor força de cisalhamento, o que foi sentido pelos provadores como maior suculência e menor dureza. Essas carnes também apresentaram menor intensidade de sabor caprino. De um modo geral, esses efeitos foram mais evidentes na carne dos animais com maior grau de mestiçagem, sendo que o grupo Boer apresentou carne de melhor qualidade que o grupo Anglo Nubiano.
\end{abstract}

Palavras-chave: carne de caprino; cor; suculência; dureza; força de cisalhamento.

\begin{abstract}
This work evaluated the quality of the meat from SRD (undesined breed) kid goats crossbred with two different genetic groups, Anglo Nubiana (A) and Boer (B). Seven animals SRD (control) were used, 07 1/2 A x 1/2 SRD, 07 3/4 A x 1/4 SRD, 07 1/2 B x 1/2 SRD, 07 3/4 B x 1/4 SRD. The studied patterns were $\mathrm{pH}\left(\mathrm{pH}_{\mathrm{o}}-30\right.$ minutes and pHf-24 hours), color ( $\left.\mathrm{L}^{*}, \mathrm{a}^{*}, \mathrm{~b}^{*}\right)$, capacity of retaining water (CRA), weight loss during cooking, resistance to shearing $(\mathrm{FC})$, succulence, hardness and flavor. The $\mathrm{pH} 30$ minutes was 6.92 for SRD, differing significantly from $\mathrm{B}$ ( 6.8 for $1 / 2$ B and 6.84 for 3/4 B). The $\mathrm{pH} 24$ hours was 5.64 for SRD, 5.42 for $1 / 2 \mathrm{~A}, 5,77$ for 3/4 A, 5.59 for $1 / 2$ B and 5.55 for $3 / 4$ B. Samples $1 / 2 \mathrm{~B}$ and $3 / 4 \mathrm{~B}$ showed different values for $\mathrm{L}^{*}$ but showed no difference for $\mathrm{a}^{*}$ and $\mathrm{b}^{*}$. The meat of crossbred animals retained more water than the control, showing lesser PPC and shearing force, which was perceived by the judges as higher juiciness and lower hardness. These samples also presented lower goat flavor. In general these effects were more evident for meat from animals with higher cross-breeding level. The Boer crossbred group showed meat with better quality than the Anglo Nubiana group.

Keywords: goat meat; color; juiciness; tenderness; shearing force.
\end{abstract}

\section{Introdução}

Os caprinos no Nordeste são criados em condições extensivas e apresentam grande capacidade de se adaptar às diferenças climáticas e às regiões. Possuem aptidão para produção de carne, leite, pele, ou ainda, aptidão mista.

Os grupos raciais de caprinos do Nordeste brasileiro são variados, predominando os mestiços e dificultando uma tipificação adequada sobre as raças ou linhagens puras. Os grupos genéticos mais estudados têm sido os animais Sem Raça Definida (SRD), originados de cruzamentos indiscriminados entre os tipos nativos e cabras asiáticas ou alpinas com

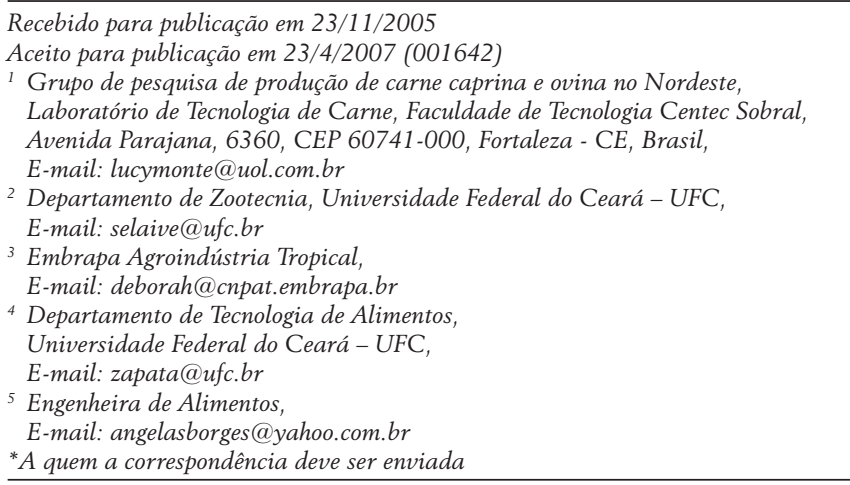

grau de mestiçagem desconhecido; raça Moxotó, que pode ser classificada como raça nativa naturalizada, e é a mais representativa da região; raça Anglo Nubiana, originária da Grã-Bretanha, proveniente do cruzamento de reprodutores ingleses com cabras nativas originárias da África e Índia; e a raça Boer, procedente da África do Sul, utilizada no melhoramento genético dos caprinos nordestinos ${ }^{32}$.

Entre as raças caprinas, a Anglo Nubiana e a Boer têm sido as mais utilizadas em cruzamentos visando o aumento da produção de carne. A raça Boer, com uma dieta de qualidade, é capaz de expressar todo seu potencial genético, pois são animais com alta taxa de prolificidade e com elevado potencial produtivo, especificamente para carne ${ }^{25}$.

Produto resultante das contínuas transformações bioquímicas que ocorrem no músculo após a morte do animal, a carne é utilizada como alimento de elevada qualidade nutricional devido à sua função plástica, influenciando na formação de novos tecidos e na regulação de processos fisiológicos e orgânicos, além do fornecimento de energia ${ }^{33}$.

A demanda por alimentos de qualidade tem aumentado nos últimos anos, fazendo com que haja uma exigência de melhoria nos setores de produção, industrialização e comercialização. 
As características de qualidade mais importantes da carne vermelha, que determinam a aceitação global do corte, são: a aparência (cor, brilho e apresentação do corte), responsável pela aceitação do consumidor no momento da compra e a maciez percebida na degustação ${ }^{2,3}$. Por outro lado, vários parâmetros de qualidade como: $\mathrm{pH}$, capacidade de retenção de água e cor são interdependentes e devem ser analisados conjuntamente. O grau de qualidade varia segundo o ponto de vista e interesse do produtor, da indústria, do comércio e principalmente do consumidor $8,21,27$.

Com o aumento do consumo das carnes caprina e ovina nos últimos anos, observa-se uma maior necessidade de oferta de produtos destas espécies, com melhor qualidade. Neste sentido, deve-se considerar que existe um grande número de fatores que afetam as características de qualidade da carne in natura e dos produtos elaborados, entre os quais podem ser citados: raça, idade, peso de abate e manejo pré e pós-abate dos animais ${ }^{7}$.

Atualmente, o mercado consumidor apresenta elevada exigência quanto à qualidade física da carne. No Brasil, ainda são escassos os dados disponíveis sobre a qualidade da carne caprina, sendo necessário intensificar as pesquisas, visando a obtenção de informações que possam contribuir para o desenvolvimento da cadeia produtiva desse tipo de carne. Diante de tal fato, o presente trabalho teve como objetivo avaliar alguns dos principais parâmetros físicos e sensoriais de qualidade da carne de cabritos mestiços com diferentes grupos genéticos.

\section{Material e métodos}

Foram avaliados 35 caprinos mestiços, oriundos de cruzamentos de reprodutores das raças Boer e Anglo Nubiana com matrizes sem raça definida (SRD), sendo sete animais SRD utilizados como controle; sete animais $1 / 2$ Anglo Nubiana $x$ 1/2 SRD (1/2 A); sete animais 3/4 Anglo Nubiana x 1/4 SRD (3/4 A); sete animais $1 / 2$ Boer $\times 1 / 2$ SRD $(1 / 2 \mathrm{~B})$ e sete animais $3 / 4$ Boer $x$ 1/4 SRD (3/4 B). O trabalho foi desenvolvido nos Departamentos de Zootecnia e Tecnologia de Alimentos da UFC, em parceria com a Embrapa Agroindústria Tropical, em Fortaleza - CE. Os animais foram mantidos em sistema semiintensivo de criação e abatidos, em média, com 10 meses de idade e $30 \mathrm{~kg}$ de peso vivo.

Após abate, evisceração e esfola dos animais, foi usado o músculo Longissimus dorsi, para medir o $\mathrm{pH}$ da carcaça quente (30 minutos pós-abate - $\mathrm{pH}_{0}$ ), e após resfriamento de 2 a $4{ }^{\circ} \mathrm{C}$ o da carcaça fria ( 24 horas post mortem - pHf), por meio de um potenciômetro digital (marca WTW, Model 300i, Berlin, Germany).

Da carcaça fria foi separado e congelado o lombo para a análise dos parâmetros físicos e sensoriais da carne. Após o descongelamento, foi retirado o músculo Longissimus dorsi (lado direito e esquerdo) para realização das análises físicas de cor $\left(L^{*}, a^{*}\right.$ e b*), perda de peso na cocção (PPC), capacidade de retenção de água (CRA), força de cisalhamento (FC) e as análises sensoriais.

A cor da carne (Sistema CIE L*a*b*) foi determinada mediante 10 leituras em 10 pontos distintos, utilizando-se um colorímetro Minolta (Chroma Meter, CR-200b, Osaka, Japão).
$\mathrm{Na}$ análise de perda de peso na cocção (PPC) foram retiradas três porções do músculo $(3,0 \times 4,0 \times 2,5 \mathrm{~cm})$, que foram pesadas em uma balança digital (Semi-analítica, Modelo BL-320H, cap. 320 g, Curitiba, Paraná) e assadas em forno pré-aquecido a $170{ }^{\circ} \mathrm{C}$, até que a temperatura no centro geométrico da carne, monitorada através de um termômetro digital (Delta OHM, modelo HD9218), atingisse $71^{\circ} \mathrm{C}$. Em seguida as amostras foram resfriadas à temperatura ambiente e novamente pesadas. As perdas durante a cocção foram expressas em porcentagem.

Após a análise de PPC, as mesmas amostras foram utilizadas para a análise de $\mathrm{FC}$, das quais foram retirados 03 cilindros por porção de carne cozida, no sentido das fibras, (totalizando 09 cilindros), com auxílio de um vazador de 1,27 cm de diâmetro. A força de cisalhamento foi registrada em um texturômetro TA-XT2 (Stable Micro System Surrey, Godalming, England).

A capacidade de retenção de água (CRA) foi determinada segundo a técnica sugerida por TROY, DESMOND e BUCKEY30.

A intensidade dos atributos sensoriais de dureza, suculência e sabor caprino foi analisada seguindo a metodologia de análise descritiva ${ }^{18}$. Inicialmente foram recrutados 20 provadores, através de um questionário que avaliou a saúde, o grau de interesse, disponibilidade de tempo, nível de aceitação da carne caprina e habilidade para descrever as características sensoriais dos atributos analisados.

Procedeu-se, então, à pré-seleção dos provadores que tiveram o poder discriminatório avaliado através do Teste Triangular, de acordo com a metodologia descrita pela ABNT ${ }^{1}$. Os provadores receberam amostras de carne com dureza intermediária ( 2 amostras) e macia ( 1 amostra), em cabines individuais, sob luz vermelha e foram orientados a avaliar as amostras e indicar qual delas era diferente, utilizando uma ficha de avaliação, conforme mostrada na Figura 1. Foi utilizada a Análise Seqüencial de Wald descrita por GARRUTI ${ }^{12}$ e SHIROSE ${ }^{24}$, com os dados de cada candidato colocados no gráfico das curvas limites de aceitação e de rejeição. Após análise dos resultados, foram selecionados 14 provadores para participarem do treinamento.

Nome: Data: / /

Você está recebendo três amostras de carne. Duas amostras são iguais e uma é diferente. Por favor, prove as amostras da esquerda para a direita e identifique com um círculo a amostra diferente quanto à TEXTURA.

Comentários:

Figura 1. Modelo da ficha do teste triangular empregada na pré-seleção dos julgadores. 
Nas sessões de treinamento foram discutidos: o objetivo do trabalho, o treinamento no uso das escalas não-estruturadas e a elaboração das definições e referências para maciez, suculência e sabor caprino. Pela dificuldade de aquisição de referências que caracterizassem o sabor caprino, os provadores ficaram à vontade para enquadrá-lo dentro da escala não-estruturada. A Tabela 1 apresenta as definições e referências de intensidade para cada atributo.

Tabela 1. Lista de definições e referências dos atributos dureza, suculência e sabor caprino.

\begin{tabular}{|c|c|c|c|}
\hline \multirow{2}{*}{$\begin{array}{c}\text { Termos } \\
\text { descritivos }\end{array}$} & \multirow[t]{2}{*}{ Definição } & \multicolumn{2}{|c|}{ Referências } \\
\hline & & Pouca & Muita \\
\hline Dureza & $\begin{array}{l}\text { Força necessária para } \\
\text { comprimir um pedaço } \\
\text { de carne entre os den- } \\
\text { tes molares, avaliada na } \\
\text { primeira mordida. }\end{array}$ & $\begin{array}{l}\text { Filé mignon } \\
\text { bovino }\end{array}$ & Peito bovino \\
\hline Suculência & $\begin{array}{l}\text { Percepção da quantida- } \\
\text { de de líquido liberado } \\
\text { da amostra de carne } \\
\text { na boca, após a quinta } \\
\text { mastigada. }\end{array}$ & $\begin{array}{l}\text { Lagarto } \\
\text { bovino }\end{array}$ & $\begin{array}{l}\text { Filé mignon } \\
\text { bovino }\end{array}$ \\
\hline Sabor caprino & $\begin{array}{l}\text { Sabor característico da } \\
\text { carne caprina. }\end{array}$ & - & - \\
\hline
\end{tabular}

Após as 5 sessões de treinamento, a equipe descritiva final foi composta pelos 10 provadores que apresentaram melhor poder discriminatório $\left(\mathrm{p}_{\text {amostra }}<0,30\right)$, boa reprodutibilidade nos julgamentos $\left(\mathrm{p}_{\text {repetiçáo }}>0,05\right)$ e consenso com os demais membros do grupo, segundo a metodologia proposta por DAMASIO e COSTELL ${ }^{9}$.

Para análise sensorial da carne caprina, as amostras foram cortadas em cubos de aproximadamente $2,0 \mathrm{~cm}$ de aresta e assadas em forno elétrico pré-aquecido a $170{ }^{\circ} \mathrm{C}$, até que a temperatura, monitorada através de um termômetro digital (Delta OHM, modelo HD9218), atingisse $71^{\circ} \mathrm{C}$ no centro geométrico da carne. Após o cozimento, os cubos foram colocados em béqueres e mantidos em aquecedores à temperatura de $50{ }^{\circ} \mathrm{C}$ até o momento da avaliação pelos provadores.
O desenho experimental utilizado foi um delineamento inteiramente casualizado. Os dados foram analisados pelo procedimento General Linears Models (GLM) do pacote estatístico do $\mathrm{SAS}^{22}$, e as médias comparadas pelo teste de Tukey.

\section{Resultados e discussão}

Os valores médios de $\mathrm{pH}\left(\mathrm{pH}_{0}=30\right.$ minutos e $\mathrm{pHf}=24$ horas), cor ( $\mathrm{L}^{*}$ - luminosidade, $\mathrm{a}^{*}$ - vermelho e $\mathrm{b}^{*}$ - amarelo), capacidade de retenção de água (CRA), perda de peso na cocção (PPC) e força de cisalhamento (FC) da carne de cabritos mestiços encontram-se na Tabela 2.

$\mathrm{O} \mathrm{pH}_{0}$ médio da carcaça quente medido aos 30 minutos post mortem foi de 6,87 , sendo os valores para os grupos $1 / 2$ B e $3 / 4$ B menores ( $p<0,05$ ) que aqueles do grupo SRD (Tabela 1). O pHf médio da carcaça fria obtido 24 horas post mortem foi de 5,60, sendo que a carne do grupo 3/4 A apresentou $\mathrm{pH}$ superior $(\mathrm{p}<0,05)$ ao dos mestiços $1 / 2 \mathrm{~A}, 1 / 2 \mathrm{~B}$ e $3 / 4 \mathrm{~B}$, mas não diferiu significativamente dos SRD. As mensurações de pH post mortem (30 minutos e 24 horas) foram semelhantes às verificadas por ARGÜELLO et al. ${ }^{3}$ em cabritos da raça Espanhola Majorera. Os valores pHf, encontraramse abaixo dos citados por DHANDA, TAYLON e MURRAY ${ }^{10}$ para carne de cabritos mestiços Boer $(5,76)$ e por BESERRA, MADRUGA e MOURA ${ }^{5}$ para carne de caprinos SRD, abatidos aos $30 \mathrm{~kg}$ de peso vivo $(5,97)$. Entre os fatores que afetam o declínio do $\mathrm{pH}$, a literatura cita: o sexo, a espécie, a raça, a idade, o estado nutricional, o stress pré-abate e a temperatura de resfriamento ${ }^{4,17}$. Visto que os animais utilizados foram todos caprinos machos inteiros, abatidos com a mesma idade e encontravam-se em estado nutricional uniforme, é provável que as diferenças estatísticas encontradas nos valores de $\mathrm{pH}$ entre os grupos genéticos estudados, possam ser atribuídas a níveis diferentes de stress no momento do abate ou a diferenças genéticas entre estes.

Os valores médios obtidos para cor foram de 35,80 para $\mathrm{L}^{*}$, 16,60 para a* e 4,20 para b* nos cabritos mestiços (Tabela 2). Valores superiores para $L^{*}(47,76)$ e b* $(13,0)$ foram relatados por TODARO et al. ${ }^{31}$ em cabritos provenientes da Sicília. Quando comparada a cor da carne dos grupos genéticos, verificou-se maior $(p<0,05)$ luminosidade $\left(\mathrm{L}^{*}\right)$ e tendência para

Tabela 2. Médias $(\mathrm{n}=7)$ e desvios padrão dos parâmetros físicos de qualidade da carne de cabritos mestiços, segundo grupo genético.

\begin{tabular}{|c|c|c|c|c|c|c|}
\hline \multirow[t]{2}{*}{ Parâmetros } & \multicolumn{5}{|c|}{ Grupos genéticos* } & \multirow{2}{*}{$\begin{array}{l}\text { Média } \\
\text { geral }\end{array}$} \\
\hline & SRD & $1 / 2 \mathrm{~A}$ & $3 / 4 \mathrm{~A}$ & $1 / 2 \mathrm{~B}$ & $3 / 4 \mathrm{~B}$ & \\
\hline \multicolumn{7}{|l|}{$\mathrm{pH}$} \\
\hline $\mathrm{pH}_{0}$ & $6,92 \pm 0,03^{\mathrm{a}}$ & $6,89 \pm 0,04^{\mathrm{ab}}$ & $6,90 \pm 0,06^{\mathrm{ab}}$ & $6,80 \pm 0,08^{c}$ & $6,84 \pm 0,06^{\mathrm{bc}}$ & 6,87 \\
\hline pHf & $5,64 \pm 0,14^{\mathrm{ab}}$ & $5,42 \pm 0,09^{c}$ & $5,77 \pm 0,08^{\mathrm{a}}$ & $5,59 \pm 0,16^{\mathrm{bc}}$ & $5,55 \pm 0,17^{\mathrm{bc}}$ & 5,60 \\
\hline \multicolumn{7}{|l|}{ Cor } \\
\hline $\mathrm{L}^{*}$ & $33,68 \pm 3,80^{c}$ & $36,20 \pm 1,66^{\mathrm{b}}$ & $37,76 \pm 2,18^{\mathrm{a}}$ & $37,07 \pm 2,29^{\mathrm{ab}}$ & $34,46 \pm 2,80^{c}$ & 35,80 \\
\hline$a^{*}$ & $18,14 \pm 1,96^{\mathrm{a}}$ & $15,79 \pm 0,87^{c}$ & $16,77 \pm 1,50^{\mathrm{b}}$ & $15,75 \pm 1,52^{\mathrm{c}}$ & $16,24 \pm 1,69^{b c}$ & 16,60 \\
\hline $\mathrm{b}^{*}$ & $5,73 \pm 0,73^{\mathrm{b}}$ & $3,01 \pm 0,07^{c}$ & $7,27 \pm 1,40^{\mathrm{a}}$ & $2,71 \pm 1,24^{\mathrm{cd}}$ & $2,19 \pm 0,30^{\mathrm{d}}$ & 4,20 \\
\hline CRA & $25,26 \pm 0,45^{c}$ & $27,51 \pm 2,31^{\mathrm{b}}$ & $29,14 \pm 0,23^{a}$ & $28,21 \pm 1,21^{\mathrm{b}}$ & $30,56 \pm 0,61^{a}$ & 28,20 \\
\hline $\mathrm{PPC}$ & $33,34 \pm 0,37^{a}$ & $28,76 \pm 1,19^{b}$ & $26,87 \pm 0,31^{c}$ & $27,05 \pm 0,80^{c}$ & $25,55 \pm 0,94^{\mathrm{d}}$ & 28,30 \\
\hline $\mathrm{FC}$ & $6,65 \pm 0,14^{\mathrm{a}}$ & $5,11 \pm 0,21^{\mathrm{c}}$ & $5,09 \pm 0,08^{c}$ & $5,77 \pm 0,39^{\mathrm{b}}$ & $4,39 \pm 0,30^{\mathrm{d}}$ & 5,40 \\
\hline
\end{tabular}

Médias seguidas de letras diferentes na mesma linha diferem estatisticamente a nível de $5 \%$, teste Tukey; ${ }^{*}$ SRD = Sem raça definida; $1 / 2 \mathrm{~A}=$ Cruzamento $1 / 2$ Anglo Nubiana x $1 / 2 \mathrm{SRD} ; 3 / 4 \mathrm{~A}=$ Cruzamento $3 / 4$ Anglo Nubiana x $1 / 4 \mathrm{SRD} ; 1 / 2 \mathrm{~B}=$ Cruzamento $1 / 2$ Boer $\times 1 / 2$ SRD; e $3 / 4$ B = Cruzamento 3/4 Bôer x 1/4 SRD. 
a cor amarela ( $\mathrm{b}^{*}$ ) nos mestiços 3/4 A que nos mestiços 3/4 B. ZEOLA, SILVA SOBRINHO e GONZAGA NETO ${ }^{34}$ argumentam que a cor da carne pode ser afetada por fatores como: o tipo de músculo, a raça, o sexo, a idade do animal e a alimentação. Quanto maiores os valores de $\mathrm{L}^{*}$, mais pálida é a carne, e quanto maiores os valores de $\mathrm{a}^{*} \mathrm{e} \mathrm{b}^{*}$, mais vermelha e amarela, respectivamente. Assim sendo, podemos considerar a carne dos SRD como a menos pálida e com maior quantidade de pigmentação vermelha. Na determinação das variáveis de cor em todos os mestiços analisados, foram utilizadas amostras de carne uniforme em relação ao tipo de músculo, sexo, idade e alimentação, isso pode sugerir que as diferenças encontradas entre os grupos se devam ao fator genético.

A capacidade de retenção de água média foi de 28,20\% (Tabela 2), sendo que a carne dos cabritos SRD reteve menor ( $\mathrm{p}<0,05)$ quantidade de água $(25,26)$ que a dos cabritos mestiços. Isso implica numa maior perda no valor nutritivo da carne pela maior quantidade de exudado liberado, resultando em carne cozida mais seca e com menor maciez. Já os mestiços 3/4 A e 3/4 B apresentaram a melhor capacidade de retenção de água (29,14 e 30,56\%, respectivamente). Razão pela qual apresentam provavelmente uma carne mais macia e com maior valor nutritivo. Os valores de capacidade de retenção de água são similares aos reportados por BESERRA, MADRUGA e MOURA ${ }^{5}$ em caprinos SRD abatidos com $30 \mathrm{~kg}$ de peso vivo (29,07\%), porém inferiores aos $38,9 \%$ relatados por MARINOVA, BANSKALIEVA e ALEXANDROV ${ }^{16}$ em cabritos na Bulgária.

A perda de peso na cocção da carne foi em média $28,30 \%$ (Tabela 2), com os maiores valores ( $\mathrm{p}<0,05$ ) observados nos cabritos SRD (33,34\%) e nos mestiços $1 / 2$ A $(28,76 \%)$, e os menores nos mestiços 3/4 B (25,55\%) e 3/4 A $(26,87)$. Estes percentuais são inferiores aos relatados na literatura para caprinos e equivalentes para ovinos de diferentes genótipos, visto que DHANDA, TAYLON e MURRAY ${ }^{10}$ em carne de cabritos mestiços Boer, encontraram valores em torno de 35,4\%, enquanto ESENBUGA, YANAR e DAYIOGLU ${ }^{11}$ em carne de cordeiros mestiços provenientes do Peru, perceberam valor de $26,6 \%$.

A perda de peso na cocção é influenciada pela capacidade de retenção de água nas estruturas da carne ${ }^{26}$, e visto que a dos animais SRD teve menor capacidade de reter água, já era de esperar que apresentasse a maior perda de água durante o processo de cocção. Em contrapartida, a carne dos mestiços 3/4 B demonstrou maior capacidade de retenção de água, conseqüentemente perdeu menos durante o processo de cocção. Isso poderia provocar uma diminuição na maciez da carne nos
SRD e uma melhoria da maciez nos mestiços 3/4 B. Durante o cozimento da carne com calor seco, a perda de peso ocorre principalmente por evaporação, o que é indesejável, pois a relação proteína:água é importante para a palatabilidade e para o rendimento adequado. KIRTON ${ }^{13}$ confirma tal fato ao dizer que a palatabilidade pode ser influenciada pelos métodos de cozimento aplicados à carne. Isso sugere que a carne dos mestiços 3/4 B pode apresentar maior rendimento na cocção.

O valor médio obtido para força de cisalhamento em carne de cabritos mestiços foi de 5,40 kg-f (Tabela 2), sendo que a dos animais $\operatorname{SRD}(6,65 \mathrm{~kg}-\mathrm{f})$, mestiços $1 / 2 \mathrm{~A}$ (5,11 kg-f) e mestiços $1 / 2$ B (5,77 kg-f) apresentaram valores maiores ( $p<0,05)$ que a dos mestiços 3/4 B (4,39 kg-f). Os valores obtidos nos cabritos são superiores aos relatados por DHANDA, TAYLON e MURRAY ${ }^{10}$, que encontraram valores de 4,2 kg-f na carne de cabritos mestiços Boer e inferior aos 7,42 kg-f relatados por SEN, SANTRA e KARIM ${ }^{23}$ em caprinos nativos da Índia. No entanto, em carne ovina, a literatura cita valor inferior, visto que na Flórida SOLOMON et al. ${ }^{28}$ encontraram cordeiros mestiços com valor de 3,4 kg-f. e PÉREZ et al. ${ }^{19}$ na África perceberam valor de 3,75 kg-f. O fato dos ovinos depositarem elevada quantidade de gordura intramuscular e os caprinos não ${ }^{16}$, pode ter contribuído para a maior maciez na carne ovina que na caprina. ARGÜELLO et al. ${ }^{3}$ considera a maciez da carne um dos mais importantes atributos de satisfação do consumidor. Considerando que, a carne com a força de cisalhamento acima de $11 \mathrm{~kg}-\mathrm{f}$ é classificada dura, entre 8 e 11 kg-f aceitável e abaixo de 8 kg-f como macia ${ }^{29}$, pode-se considerar que as carnes dos cabritos em estudo são macias.

Entre os fatores que afetam a maciez de uma espécie destacam-se: a raça, o tipo de músculo e o grau de cocção. Como na determinação da força de cisalhamento utilizou-se o mesmo músculo e aplicou-se o mesmo processo de cocção em todas as carnes, as diferenças estatísticas encontradas entre os grupos podem ser atribuídas ao fator genético.

Como era de esperar, os animais do grupo SRD, por terem apresentado uma menor capacidade de retenção de água e uma maior perda de água durante a cocção, apresentaram uma maior força de cisalhamento. Comportamento inverso foi observado nos cabritos 3/4 Boer, nos quais a carne apresentou maior capacidade de retenção de água, menor perda durante a cocção, e conseqüentemente, menor força de cisalhamento, indicando maior maciez que a dos demais grupos estudados.

As características sensoriais de dureza, suculência e sabor caprino da carne de cabritos mestiços encontram-se na Tabela 3. Nas características sensoriais, a carne dos cabritos mestiços apresentou valores médios de 2,88, 5,45 e 4,05 para

Tabela 3. Médias ( $\mathrm{n}=7$ ) e desvios padrão dos parâmetros sensoriais de qualidade da carne de cabritos mestiços, segundo grupo genético.

\begin{tabular}{|c|c|c|c|c|c|c|}
\hline \multirow[t]{2}{*}{ Parâmetros } & \multicolumn{5}{|c|}{ Grupos genéticos* } & \multirow[t]{2}{*}{ Média geral } \\
\hline & SRD & $1 / 2 \mathrm{~A}$ & $3 / 4 \mathrm{~A}$ & $1 / 2 \mathrm{~B}$ & $3 / 4 \mathrm{~B}$ & \\
\hline Dureza & $4,54 \pm 0,5^{\mathrm{a}}$ & $2,59 \pm 0,87^{c}$ & $2,52 \pm 0,36^{c}$ & $3,37 \pm 0,08^{\mathrm{b}}$ & $1,40 \pm 1,03^{\mathrm{d}}$ & 2,88 \\
\hline Suculência & $4,29 \pm 0,55^{\mathrm{d}}$ & $5,34 \pm 0,57^{c}$ & $5,71 \pm 0,63^{b}$ & $5,33 \pm 0,75^{\mathrm{c}}$ & $6,57 \pm 0,71^{\mathrm{a}}$ & 5,45 \\
\hline Sabor caprino & $5,44 \pm 0,56^{a}$ & $4,09 \pm 0,50^{\mathrm{a}}$ & $3,82 \pm 0,52^{\mathrm{bc}}$ & $3,71 \pm 0,80^{b c}$ & $3,19 \pm 0,66^{c}$ & 4,05 \\
\hline
\end{tabular}

Médias seguidas de letras diferentes na mesma linha diferem estatisticamente a nível de $5 \%$, teste Tukey; *SRD = Sem raça definida; $1 / 2$ A = Cruzamento $1 / 2$ Anglo Nubiana x $1 / 2 \mathrm{SRD} ; 3 / 4 \mathrm{~A}=$ Cruzamento $3 / 4$ Anglo Nubiana $\times 1 / 4 \mathrm{SRD} ; 1 / 2 \mathrm{~B}=$ Cruzamento $1 / 2$ Boer $\times 1 / 2$ SRD; e $3 / 4 \mathrm{~B}=$ Cruzamento $3 / 4$ Bôer x 1/4 SRD 
dureza, suculência e sabor caprino, respectivamente (Tabela 3). A carne dos SRD apresentou maior valor para dureza $(4,54) \mathrm{e}$ sabor caprino $(5,44)$, e menor valor para suculência $(4,29)$ que a dos mestiços 3/4 B. A carne dos mestiços 1/2 B (3,37) apresentou-se mais dura $(\mathrm{p}<0,05)$ que a dos mestiços $1 / 2$ Anglo $(2,59)$. A dos mestiços $3 / 4 \mathrm{~A}$, por outro lado, se apresentou mais dura $(\mathrm{p}<0,05)$ e menos suculenta $(\mathrm{p}<0,05)$ que a dos mestiços 3/4 B. Em caprinos nativos da Índia, SEN, SANTRA e KARIM ${ }^{23}$, utilizando painel treinado e escala sensorial com pontuação máxima de 5 pontos, observaram valor de 4,0 pontos para sabor caprino. Considerando que, a escala não-estruturada utilizada na carne dos cabritos mestiços Boer, Anglo e SRD apresentou pontuação máxima de 9 pontos, podemos inserir que as carnes destes apresentam sabor caprino menos acentuado.

BORGES et al. ${ }^{6}$, com painel treinado e escala não-estruturada, observaram em caprinos mestiços (Boer x SRD) valores semelhantes para a suculência $(5,0)$. Para este atributo, a literatura relata valores equivalentes na carne ovina, visto que PONNAMPALAM et al. ${ }^{20}$, em ovinos da Austrália, verificaram média 5,7 e ESENBUGA, YANAR e DAYIOGLU ${ }^{11}$, em cordeiros do Peru, encontraram valor de 5,5. O resultado encontrado está dentro do esperado, uma vez que os mestiços 3/4 B apresentaram menor perda de peso na cocção, menor força de cisalhamento e maior capacidade de retenção de água. Pode-se observar, que as amostras com menor intensidade de dureza apresentaram (Tabela 3) também menor valor da força de cisalhamento (Tabela 2).

O sabor e o aroma característicos da carne de cada espécie está relacionado ao teor de gordura no músculo ${ }^{15}$. Em estudos com ovinos Santa Inês, MADRUGA et $\mathrm{al}^{15}$ verificaram sabor mais intenso na carne dos animais que apresentaram maior teor de gordura no músculo.

Em pesquisas sensoriais de carne caprina, uma das observações mais constantes tem sido a ausência de sabor, freqüentemente associada à falta de maciez e suculência, levando a uma impressão geral desfavorável do produto ${ }^{14}$. Diante dos dados oriundos desta pesquisa, podemos sugerir que o cruzamento entre raças nativas com baixa aptidão genética para produção de carne com raças de elevado potencial para produção de carne podem melhorar significativamente os atributos sensoriais da carne caprina.

\section{Conclusões}

Os mestiços Boer apresentaram carne de melhor qualidade física e sensorial, assim, o cruzamento com a raça Boer constitui-se uma ferramenta importante para o produtor na melhoria da qualidade da carne.

A carne de cabritos mestiços Anglo Nubiana e Boer pode ser considerada de maior maciez em relação à carne dos cabritos SRD, melhorando à medida que aumenta o grau de mestiçagem.

É necessário intensificar as pesquisas, visando a obtenção de informações que possam contribuir para o desenvolvimento da cadeia produtiva da carne caprina.

\section{Referências bibliográficas}

1. ASSOCIAÇÃO BRASILEIRA DE NORMAS TÉCNICAS. NBR 12995: Teste triangular em análise de alimentos e bebidas, 1993.

2. AlCADE, M. J.; NEGUERUElA, A. I. The influence of final conditions on meat colour in light lamb carcasses. Meat Science, n. 57, p. 117-123, 2001.

3. ARGÜELLO, A. et al. Effects of diets and live weight at slaughter on kids meat quality. Meat Science, n. 70, p. 173-179, 2005.

4. AZEVEDO, P. R. A. O valor nutricional da carne. Revista Nacional da Carne, São Paulo, v. 37, n. 327, p.18-33, 2004.

5. BESERRA, F. J; MADRUGA, M. S; MOURA, R. P. Características químicas e físico-químicas da carne de caprinos SRD com diferentes pesos de abate. Revista Nacional da Carne, São Paulo, v. 3, n. 2, p. 1-7, 2001.

6. BORGES, A. S. et al. Medições instrumentais e sensoriais de dureza e suculência na carne caprina. Ciência Tecnologia de Alimentos, Campinas, v. 26, n. 4, p. 891-896, 2006.

7. BRESSAN, M. C.; PRADO, O. V.; PÉREZ, J. R. O. Efeito do peso ao abate de cordeiros Santa Inês e Bergamácia sobre as características físico-químicas da carne. Ciência Tecnologia de Alimentos, Campinas, v. 21, n. 3, p.293-303, 2001.

8. DABÉS, A. C. Propriedades da carne fresca. Revista Nacional da Carne, São Paulo, v. 25, n. 288, p. 32-40, 2001.

9. DAMASIO, M. H.; COSTELL, E. Analisis sensorial descriptivo; generación de descriptores y selección de catadores. Rev. Agrop. Tecnol. Alim., v. 31, n. 2, p. 165-178, 1991.

10. DHANDA, J. S.; TAYLOR, D. G.; MURRAY, M. J. Part 1. Growth, carcass and meat quality parameters of male goats: effects of genotype and live weight at slaughter. Small Ruminant Research v. 50, p. 57-66, 2003.

11. ESENBUGA, N.; YANAR, M.; DAYIOGLU, H. Physical, chemical and organoleptic properties of ram lamb carcasses from four fattailed genotypes. Small Ruminant Research. v. 39, p. 99-105, 2001.

12. GARRUTI, R. S. Metodologia na seleção seqüencial e não seqüencial para equipes de provadores. 1976. Tese (Doutorado em Ciências de Alimentos) - Faculdade de Engenharia de Alimentos e Agrícola, Universidade Estadual de Campinas, Campinas.

13. KIRTON, A. H. Carcass and meat qualities. in: COLlEGE, L. Sheep and Goat Production. New Zealand: COOP, 1982. cap. 14 p. 259-274.

14. MADRUGA, M. S. et al.Castrations and slaughter age effects on panel assessment and aroma compounds of the mestiço goats meat. Meat Science, n. 56, p. 117-125, 2000.

15. MADRUGA, M. S. et al. Qualidade das carne de cordeiros Santa Inês terminados com diferentes dietas. Revista Brasileira de Zootecnia, São Paulo, v. 34, n. 1, p. 309-315, 2005.

16. MARINOVA. P., BANSKALIEVA, V., ALEXANDROV, S. Carcass composition and meat quality of kids fed sunflower oil supplemented diet. Small Ruminant Research. v. 42, p. 219-227, 2001.

17. McGEEHIN; SHERDAN, J. J.; BUTLER, F. Factors affecting the $\mathrm{pH}$ decline in lamb after slaughter. Meat Science, n. 58, p. 79-84, 2001.

18. POSTE, L. M. et al. Laboratory methods for sensorial analisis of food. Research brach Agricultuta. Canada, p. 92, 1991. 
19. PÉREZ, P. et al. Carcass characteristics and meat quality of Suffolk Down suckling lambs. Small Ruminant Research. v. 44, p. 233-240, 2002.

20. PONNAMPALAM, E. N.; SINCLAIR, A. J.; EGAN, A. R.; FERRIER, G. R.; LEURY, B. J. Dietary manipulation of muscle long-chain omega-3 and omega- 6 fatty acids and sensory properties of lamb meat. Meat Science, n. 60, p. 125-132, 2002.

21. ROÇA, R. O. Alternativas de aproveitamento da carne ovina. Revista Nacional da Carne, São Paulo, v. 18, n. 201, p. 53-60, 1993.

22. SAS - STATISTICAL ANALYSIS SYSTEM User's guide: Statistics, Cary: SAS INSTITUTE, 956 p, 1998.

23. SEN, A. R.; SANTRA, A.; KARIM, S. A. Carcass yield, composition and meat quality attributes of sheep and goats under semiarid condition. Meat Science, n. 66. p.757-763, 2004.

24. SHIROSE, I. Análise Seqüencial de Wald e sua Aplicação à seleção de julgadores para avaliação organoléptica. Boletim do ITAL, v. 50, março/abril, p. 57-77, 1977.

25. SHRESTH, J. N. B; FAHMY, M. H. Breeding goats for meats production: a review. 1. Genetic resources, management and breed evaluation. Small Ruminant Research, v. 58, p. 93-106, 2005.

26. SILVA SOBRINHO, A. G.; PURCHAS, R. W.; KADIM, I. T.; YAMAMOTO, S. M. Características de qualidade da carne de ovinos de diferentes genótipos e idades ao abate. Revista Brasileira de Zootecnia, São Paulo, v. 34, n. 3, p. 1070-1078, 2005.
27. SIQUEIRA, E. R.; ROÇA, R. O.; FERNANDES, S.; UEMI, A. Características sensoriais da carne de cordeiros da raça Hampshire Down, Santa Inês e mestiços Bergamácia x Corriedale abatidos com quatro distintos pesos. Revista Brasileira de Zootecnia, São Paulo, v. 31, n. 3, p.1269-1272, 2002.

28. SOLOMON, M. B. et al. Effect of breed and slaughter weight on physical, chemical and organoleptic properties of lamb carcasses. Journal of Animal Science, v. 51, n. 5. p. 1102-1107, 1980.

29. SOUZA, X. R. et al. Efeitos do grupo genético, sexo e peso ao abate sobre as propriedades físico-químicas da carne de cordeiros em crescimento. Ciência Tecnologia de Alimentos, Campinas, v. 24 , n. 4, 2004.

30. TROY, D. J., DESMOND, E. M., BUCKEY, D. Eating Quality of Low-Fat beef urges containing Fat - Replacing functional blebs. J. Sci. Food Agri., v. 12, p. 507-516, 1999.

31. TODARO, M. et al. The influence of age at slaughter and litter size on some quality traits of kid meat. Small Ruminant Research. v. 44 , p. $75-80,2002$.

32. ZAPATA, J. F. F.; SEABRA, L. M. J; NOGUEIRA, C. M; BEZERRA, L. C.; BESERRA, F. J. Características de carcaça de pequenos ruminantes do nordeste do Brasil. Ciência Animal, v. 11, n. 2, p. 79-86, 2001.

33. ZEOLA, N. M. B. L. Conceitos e parâmetros utilizados na avaliação da qualidade da carne ovina. Revista Nacional da Carne, São Paulo, v. 304. n.25, p.36-56, 2002

34. ZEOLA, N. M. B. L; SILVA SOBRINHO, A. G; GONZAGA NETO, S. Influência de diferentes níveis de concentrado sobre a qualidade da carne de cordeiros Morada Nova. Revista Portuguesa de Ciências Veterinárias, v. 97, n. 544, p.175-180, 2002. 